\title{
STUDY OF NORMAL VALUES OF EVAN'S INDEX ON BRAIN GT SCAN IN INDIVIDUALS ATTENDING NEPAL MEDICAL COLLEGE TEACHING HOSPITAL, KATHMANDU, NEPAL
}

\author{
Pradhan A, Chalise U, Shrestha A, Dhungel S
}

Department of Anatomy, Nepal medical college teaching hospital, Kathmandu, Attarkhel, Gokarneshwor-8, Kathmandu, Nepal

\begin{abstract}
Ventriculographic indices are obtained by using Evan's Index. Evan's Index is a ratio which compares the maximum width of the frontal horns of the lateral ventricle to the maximum transverse diameter of the inner table of the skull and serves as an indirect marker of ventricular volume. Evan's Index has been extensively used in the diagnosis of idiopathic normal pressure hydrocephalus, in the assessment of outcome of patients having shunt placement which is the primary mode of treatment. This study was aimed to find out the normal values of Evan's Index on brain CT scan in individuals attending Nepal medical college teaching hospital, Kathmandu, Nepal. A total of 500 individuals CT (250 males and 250 females) were finally selected. The ages were ranged between 5 to 80 years old. The mean Evan's Index in the studied population was $0.253 \pm 0.037$ in males, $0.250 \pm 0.034$ in the females and an overall mean of $0.251 \pm 0.035$. There was no significant statistical difference in the Evans ratio between male and females $(\mathrm{P}=0.274)$. This study shows that Evan's Index was higher in individuals who were 60 years and above in both males and females. The very small standard deviations appreciated in the result suggest that Evan's index can be calculated fairly accurately.
\end{abstract}

\section{KEYWORDS}

Lateral ventricle, computerized tomography (CT), Evan's Index, Normal pressure hydrocephalus.

\section{CORRESPONDING AUTHOR}

Dr. Allin Pradhan,

Assistant professor,

Department of Anatomy,

Nepal Medical College Teaching Hospital, Attarkhel,

Gokarneshwor-8, Kathmandu, Nepal

Email: meallinsh@gmail.com

Orcid No: https://orcid.org/0000-0002-7691-2335

DOI: https:/www.doi.org/10.3126/nmcj.v23i1.36227 


\section{INTRODUCTION}

The ventricular system of central nervous system is responsible for transporting the cerebrospinal fluid which is produced by the ependymal cells and choroid plexus and it also protects the brain from trauma., ${ }^{1,2}$ Ventricles constitute $2 \%$ of brain volume. Eighty-two percent of the ventricular volume is contributed by lateral ventricles. ${ }^{3}$ Ventricular enlargement caused due to imbalance in the production and absorption of cerebrospinal fluid is referred as hydrocephalus..$^{4,5}$ Cerebal ventricular enlargement is one of the characteristic in cerebral disorders associated with neurologic and psychiatric involvements. It has been demonstrated as encephalographic abnormality both in children and adults. ${ }^{6}$

Previously practiced radiographic methods (gas or contrast encephalography) were invasive and having artifacts. ${ }^{7}$ To overcome these limitations newer neuro imaging techniques in the form of CT and MRI has led to better attempts at evaluating ventricular measurements. ${ }^{8-10}$

Ventriculographic indices are obtained by using Evan's Index (EI). Evan's Index is a ratio which compares the maximum width of the frontal horns of the lateral ventricle to the maximum transverse diameter of the inner table of the skull and serves as an indirect marker of ventricular volume. ${ }^{11,12}$

The international guidelines for the diagnosis of normal pressure hydrocephalus (NPH) define ventricular enlargement as Evan's Index greater than $0.3 .{ }^{12}$

Evan's Index has been extensively used in the diagnosis of idiopathic normal pressure hydrocephalus, in the assessment of outcome of patients having shunt placement which is the primary mode of treatment, ${ }^{9}$ and also helping to assess the visual complications on childhood hydrocephalus. ${ }^{13}$ This study was aimed to find out the normal values for Evan's index on brain CT scan in individuals attending Nepal Medical College Teaching Hospital, Kathmandu, Nepal.

\section{MATERIALS AND METHODS}

This is a record -base, cross-sectional, non interventional study. The study was conducted in Nepal Medical College and Teaching Hospital, Attarkhel, Gokarneshwor-8, Kathmandu, Nepal from August 2020 - September 2021. Ethical consideration does not permit that healthy individuals with no clinical symptoms be subjected to ionizing radiation. Therefore, CT scans of neurologic patients which were reported to be normal were reviewed for this study. Being a record-base study, patient consent was not required however; this research was approved by the ethics committee Nepal medical college and Teaching Hospital and permission was obtained from the hospital authorities. Based on the study of Hamidu et al. ${ }^{14}$ Evan's Index at 95\% confidential level taking standard deviation of $3 \mathrm{~mm}$ and margin of error of $0.27 \mathrm{~mm}$, the sample size was calculated as 500 using the formula $n=Z^{2} \sigma^{2} / d^{2}$ Being a retrospective study, patient consent was not required however; this research was approved by the ethics committee Nepal medical college and Teaching Hospital. Scan reports of 500 individuals that were reported excluding abnormality in CT brain were reviewed independently by investigators alongside their images with taking help when needed by radiology expert. A total of 500 individual CT (250 male and 250 female) were finally selected and subjected to analysis for the study, whose ages were ranged between 5 to 80 years old. CT were performed using Toshiba Aquilion 64-slice optima CT using tube Voltage $120-140 \mathrm{kVp}$, collimation of $2 \mathrm{~mm}$, tube current of 125-210 mAs, slice thickness of $0.5 \mathrm{~mm}$ and pitch $0.65 \mathrm{~mm}$. The images were viewed on the computer monitor using a meter rule with which the following measurements were made ${ }^{14}$ as shown in Fig. 1. Evan's Index ratio were obtained by measuring maximum frontal horn width to the maximum transverse diameter of the inner table in the same section (Fig. 1).

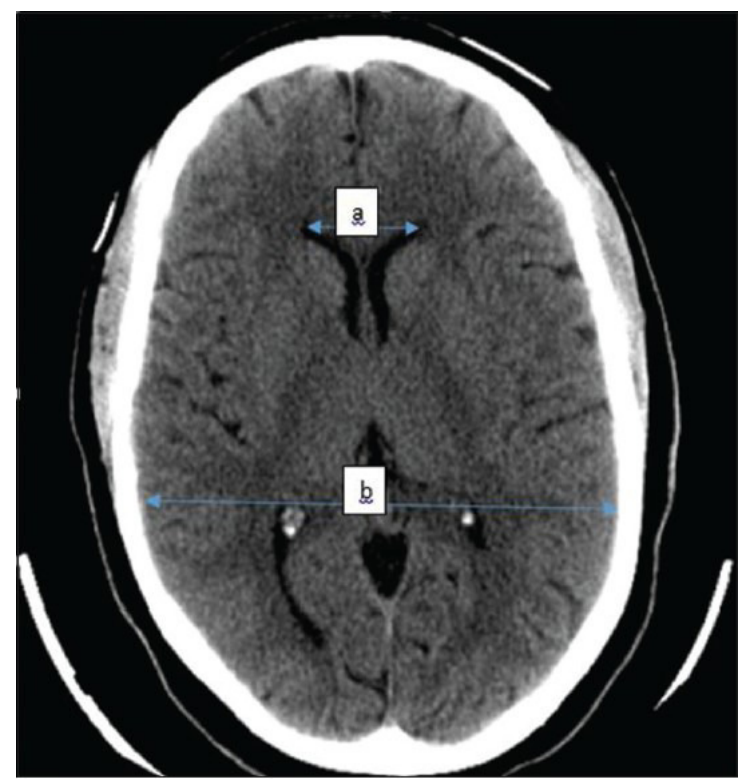

Fig. 1: Illustrative axial brain CT section of one of the selected individual showing how measurements were taken. Total anterior horn width $($ TAHW $)=$ a and Maximum intracranial diameter $(\mathrm{MICD})=\mathrm{b}$ 


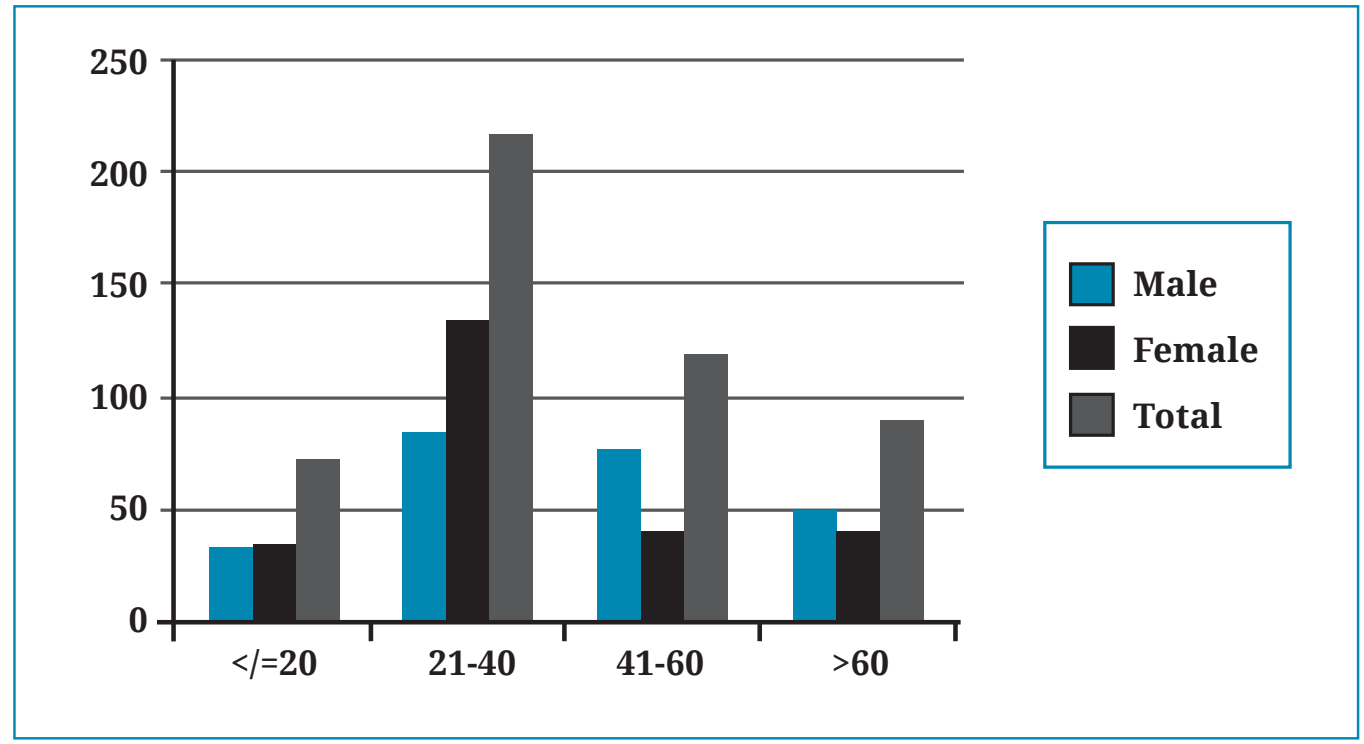

Fig. 2: Age and sex distribution of study population

\begin{tabular}{|lccccc|}
\multicolumn{7}{c|}{ Table 1: Gender- Specific ventricular dimensions } \\
& \multicolumn{7}{c}{ Overall } & Male & Female & Mean difference & P - value \\
\hline TAHW $(\mathrm{cm})$ & $3.210 \pm 0.495$ & $3.276 \pm 0.518$ & $3.143 \pm 0.464$ & $0.133 \pm 0.440$ & 0.003 \\
MICD $(\mathrm{cm})$ & $12.728 \pm 0.682$ & $12.891 \pm 0.637$ & $12.565 \pm 0.688$ & $0.326 \pm 0.593$ & $\leq 0.001$ \\
Evan's Index & $0.251 \pm 0.035$ & $0.253 \pm 0.037$ & $0.250 \pm 0.034$ & $0.003 \pm 0.003$ & 0.274 \\
\hline
\end{tabular}

Table 2: Age and Sex distribution of ventricular parameter.

\begin{tabular}{|lccccc|}
\hline Age Group (Years) & Sex & Number & TAHW & MICD & Evan Index \\
\hline \multirow{3}{*}{$<0$} & M & 38 & $2.984 \pm 0.774$ & $12.967 \pm 0.833$ & $0.229 \pm 0.052$ \\
& F & 35 & $2.689 \pm 0.710$ & $12.377 \pm 0.814$ & $0.217 \pm 0.055$ \\
\multirow{3}{*}{$21-40$} & OVERALL & 73 & $2.842 \pm 0.753$ & $12.684 \pm 0.870$ & $0.223 \pm 0.054$ \\
& M & 84 & $3.281 \pm 0.411$ & $12.780 \pm 0.675$ & $0.256 \pm 0.029$ \\
& F & 134 & $3.173 \pm 0.332$ & $12.545 \pm 0.648$ & $0.252 \pm 0.024$ \\
$41-60$ & OVERALL & 218 & $3.214 \pm 0.367$ & $12.636 \pm 0.667$ & $0.253 \pm 0.262$ \\
& M & 78 & $3.215 \pm 0.435$ & $12.831 \pm 0.485$ & $0.249 \pm 0.249$ \\
& F & 41 & $3.225 \pm 0.365$ & $12.640 \pm 0.570$ & $0.254 \pm 0.268$ \\
$>60$ & OVERALL & 119 & $3.219 \pm 0.411$ & $12.765 \pm 0.521$ & $0.251 \pm 0.032$ \\
& M & 50 & $3.587 \pm 0.394$ & $13.115 \pm 0.564$ & $0.273 \pm 0.027$ \\
& F & 40 & $3.358 \pm 0.422$ & $12.718 \pm 0.785$ & $0.267 \pm 0.028$ \\
& OVERALL & 90 & $3.485 \pm 0.420$ & $12.939 \pm 0.696$ & $0.270 \pm 0.028$ \\
\hline
\end{tabular}

Total Anterior horn width (TAHW): a | Maximum intracranial diameter (MICD): b |Evan's index (EI) derived by calculation for each patient as $=$ TAHW $/$ MICD 


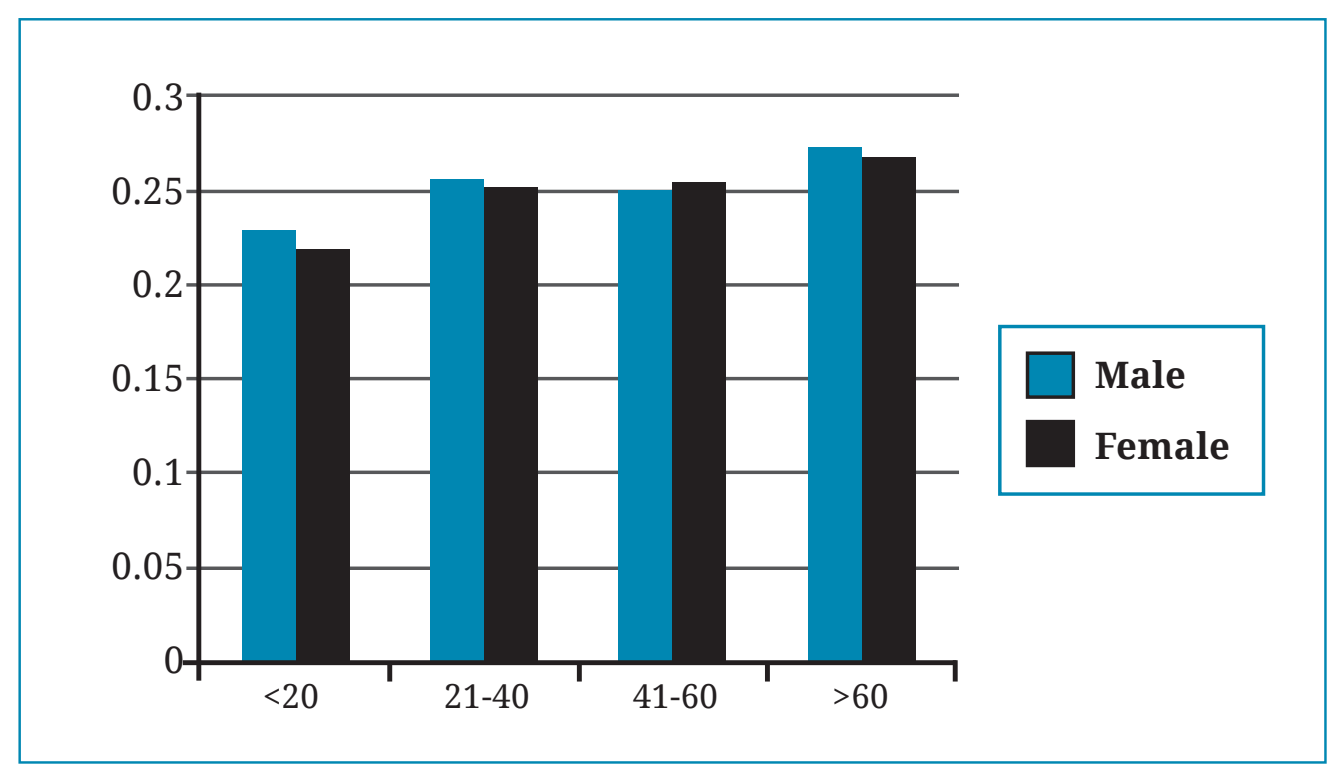

Fig. 3: Evans index in different age groups

Statistical analysis: As for Statistical analysis, data analysis was done using Statistical Package for Social Sciences (SPSS) version 16.Data are presented in tables and charts, and expressed as percentage, means and standard deviation. Significance was determined using the independent sample t-test for quantitative variables used in the study. $P$ value of $<0.05$ was considered statistically significant.

\section{LIMITATION AND DELIMITATION}

1. Ethical consideration does not permit to obtain desired data by subjecting healthy individuals to have $\mathrm{CT}$ with no clinical symptoms. (subjecting them to ionizing radiation)

2. Hence, CT scans of individuals, who underwent this procedure and having normal reports were reviewed for this study.

- $\quad$ TAHW(cm)- Total anterior horn width

- $\operatorname{MICD}(\mathrm{cm})$ - Maximum intracranial diameter

- SD-Standard deviation

\section{RESULTS}

These results were obtained from the analysis of 500 brain CT scans that were finally selected; their age and sex distribution is seen in Fig. 2. Table 1 describes, the mean Evan's Index in the studied population was $0.253 \pm 0.037$ in males, $0.250 \pm 0.034$ in the females and an overall mean of $0.251 \pm 0.035$. There was no significant statistical difference in the Evans ratio between male and females $(P=0.274)$. Ventricular dimension was significantly lower in case of female however there were no significantly difference in ratio. while in Table 2 Evan's
Table 3: comparison of Evans Index between similar studies

\begin{tabular}{|lc|} 
Authors & Evan's Index \\
$\begin{array}{l}\text { Sari E et al., [2](paediatric } \\
\text { sample) }\end{array}$ & $0.23+0.28$ \\
Jehangir M et al., [5] & $0.264+0.03$ \\
Hamidu AU et al., [14] & $0.252+0.04$ \\
Reddy U V et al.,[15] & $0.25 \pm 0.02$ \\
Patnaik P et al., [26] & $0.252+0.04$ \\
Kumar S A et al., [28] & $0.27+0.03$ \\
Present study & $0.251 \pm 0.035$ \\
\hline
\end{tabular}

Index, total anterior horn width and maximum intracranial diameters are shown with respect to age and sex of the patients and this table also shows that Evan's Index was highest in individuals who were 60 years and above in both males and females. The distribution of Evan's Index among the different age groups in both sexes is depicted in a grouped bar chart in Fig. 3, the bars representing the standard deviation.

\section{DISCUSSION}

Evan's ratio was originally obtained by dividing the transverse diameter of the anterior horns of the ventricles by the maximum internal diameter of the skull on encephalographic films. ${ }^{15}$ The wider availability of the CT scan makes it an easy to use modality to measure the size of the ventricular system, ${ }^{16}$ particularly 
in resource limited settings and where the affordability is a major constraint.

Ventricular enlargement in adults could be as a result of aging, neurodegenerative diseases, cerebro-vascular conditions, tumors and trauma. $^{13,14,17,18}$ EI is a quantitative criterion which has been used extensively in assessing ventriculomegaly and the mean value in this study is consistant with those of previous Caucasian studies. We also found that EI increased with advancing age as reported by other authors. ${ }^{19,20}$ This is due to the fact that the brain substance shrinks with age, while the cerebrospinal fluid spaces which include the ventricles increase in size in order to compensate for the atrophying brain parenchyma. With this physiologic ventricular enlargement, the Evans ratio does not exceed 0.3. Haug ${ }^{21}$ EI as measured by CT or MRI on the other hand quantitatively assesses the degree of ventricular enlargement, with an international guideline diagnostic cut off value of $>0.3{ }^{12}$ Evan's suggested that in a "normal" group the ratio between 0.20 and 0.25 was most common and it was shown statistically that this ratio was not influenced by the age or by the size of the skull. ${ }^{15}$ Values between 0.25 and 0.30 were considered borderline enlargement and values above 0.30 were suggested as a pathological dilatation of the ventricles. ${ }^{15,22}$ These observations have been confirmed by many authors in the past ${ }^{11,23,24}$ Kosourov et $a l .{ }^{25}$, in 2002, in their study observed a mean Evan's Index ranging from 0.22 to 0.28 in adults. Our data also are in agreement with the literature that the normal value of mean Evan's Index in adults ranges from 0.22 to $0.28 .1 .15,25$ According to Reddy $\mathrm{V}^{15}$ Although they had 14 person with Evan's index $>0.30$, none of them had symptoms related to ventriculomegaly and mean Evan Index was $0.25 \pm 0.02$, we also had 24 persons with Evan's index $>0.30$, none of them also had symptoms related to ventriculomegaly and mean Evan Index was 0.25 \pm 0.03 . Hamidu et $a .^{14}$, in 488 subjects of adult Nigerian population observed an increase of Evan's Index with advancing age with mean EI of 0.252 $\pm 0.04 .{ }^{14}$ Similar increase of EI with advancing age is observed in our study too (Table 2; Fig3 ) and with similar mean EI $0.251 \pm 0.035$. In the Indian study by Patnaik et al. ${ }^{26}$, in 120 patients however mean EI was $0.27 \pm 0.035$ and statistically significant difference was noted in the EI value between males and females in study by Patnaik et $a^{26}$ with EI value of $0.28 \pm$ 0.04 in males and $0.26 \pm 0.03$ in females, ${ }^{26}$ but in our study, no statistically significant difference was observed in EI value between males and females, with EI value $0.25 \pm 0.037$ in males, $0.25 \pm 0.034$ in the females which is similar to Nigerians study ${ }^{14} 0.25 \pm 0.04$ in males, $0.25 \pm$ 0.04 in the females. Women have smaller brain size, around 110-115 gm lesser than males. As compared to males, they also have smaller lateral ventricles with proportionately smaller cerebral hemispheric size. ${ }^{27}$ The absence of statistically significant difference in EI value between males and females in our study could probably be attributed to proportionately smaller size of lateral ventricles and cerebral hemispheric size in females. The very small standard deviations appreciated in the result suggest that Evan's index can be calculated fairly accurately.

Another South Indian study by Arun et $a l^{28}$ in 100 patients shows mean EI as $0.27 \pm 0.035$ and another Indian study by Patnaik et $a l^{29}$ in 60 patients also shows mean EI as $0.27 \pm 0.035$. Evan index of $>0.30$ is the cut-off value for the diagnosis of hydrocephalus as per international guidelines. ${ }^{12,30}$ According to the study by Synek et $a l^{31}$ and Gwaler et $a l,{ }^{7}$ normal EI should be 0.29 or lower. Kosourov et $a l^{25}$ in 2002, in their study observed a mean Evan's Index ranging from 0.22 to 0.28 in adults.

Although Evan's index is known as an objective measurement tool for the ventricular volume to diagnose ventriculomegaly, now with the advancements in imaging techniques, many other better measurement systems to describe the size of the ventricular have been discussed (to name a few, Huckman Number, Bicaudate-Frontal (ventricular) Index, Schiersmann's Index, Bicaudate Index). ${ }^{32}$ Many of these tools (volumetry, which measures the intraventricular volume) may need advanced imaging modalities (i.e. MRI), are time consuming, and partially operator dependent. $^{33,34}$

In conclusion, our study has shown the normal range of Evan's index in individuals attending Nepal Medical College Teaching Hospital with respect to age and sex. Mean Evan Index of 0.251 \pm 0.035 in our study supports the adaptation of international guideline cut -off value of Evan Index $>0.30$ in the diagnosis of hydrocephalus among individuals attending Nepal Medical College Teaching Hospital as well. Evan Index is less technical, easily reproducible, less time consuming and can be used in routine practice. 


\section{REFERENCES}

1. Bisht A, Suri A, Bansal S, Chandra PS, Kumar R, Singh M, Sharma BS: Factors affecting surgical outcome of endoscopic third ventriculostomy in congenital hydrocephalus. J Clin Neuro Sci 2014; 21: 1483-9.

2. Sarı E, Sarı S, Akgün V et al. Measures of ventricles and Evans' Index: From neonate to adolescent. Pediatr Neurosurg 2015; 50: 12-7.

3. Akdogan I, Kiroglu Y, Onur S, Karabuluti N. The volume fraction of brain ventricles to total brain volume: a computed tomography stereological study. Folia Morphol (Warsz) 2010; 69: 193-200.

4. Haslam RHA. Hydrocephalous. In: Behrman RE, Kliegman RM, Nelson WE, Vaughan VC. (eds). Nelson Text Book of Pediatrics, 14th edition. Philadelphia, W.B. Saunders Co 1992; page 1487.

5. Jehangir M, Dar IH, Sahota A, Hassan GH, Mustafa K, Javaid A. Normative Parameters of Evans Index using Computerized Tomographic Scan in Individuals of Kashmiri Ethnicity. Int'l J Cont Med Res 2018; 6: 77-83.

6. Evans WA., Jr An encephalographic ratio for estimating ventricular enlargement and cerebral atrophy. Arch Neurol Psychiatr 1942; 47: 931-7.

7. Gawler J, Du Boulay GH, Bull JW, Marshall J. Computerized tomography (The EMI scanner): A comparison with pneumoencephalography and ventriculography. I Neurol Neurosurg Psychiatr 1976; 39: 203-11.

8. Anik Y, Demirci A, Anik I, Etus V, Arslan A. Apparent diffusion coefficient and cerebrospinal fluid flow measurements in patients with hydrocephalus. J Comput Assist Tomogr 2008; 32: 392-6.

9. Hashimoto M, Ishikawa M, Mori E, Kuwana N. Study of INPH on Neurological Improvement (SINPHONI). Diagnosis of idiopathic Normal pressure hydrocephalus is supported by MRI-based scheme: A prospective cohort study. Cerebrospinal Fluid Res 2010; 7: 18.

10. Moore DW, Kovanlikaya I, Heier LA et al. A pilot study of quantitative MRI measurements of ventricular volume and cortical atrophy for the differential diagnosis of normal pressure hydrocephalus. Neurol Res Int'l 2012; 2012: doi:10.1155/2012/718150

11. Ambarki K, Israelsson $\mathrm{H}$, Wåhlin $\mathrm{A}$, Birgander $\mathrm{R}$, Eklund A, Malm J. Brain ventricular size in healthy elderly: Comparison between Evans index and volume measurement. Neurosurg 2010; 67: 94-9.

12. Toma AK, Holl E, Kitchen ND, Watkins LD. Evans' index revisited: The need for an alternative in normal pressure hydrocephalus. Neurosurg 2011; 68: 939-44.

13. Idowu OE, Balogun MM. Visual function in infants with congenital hydrocephalus with and without myelomeningocoele. Childs Nerv Syst 2014; 30: 327-30.

14. Hamidu AU, Olarinoye-Akorede SA, Ekott DS, Danborno B, Mahmud MR, Balogun MS. Computerized tomographic study of normal
Evans index in adult Nigerians. J Neurosci Rural Pract 2015; 6: 55-8. 14

15. Reddy VU, Hegde KV, Agrawal A, Pathapati RM, Arumulla M. Normative values for Evan's index on CT scan for apparently healthy individuals. $J$ Anat Soc India 2015; 64: 137-4 15

16. DeCarli C, Kaye JA, Horwitz B, Rapoport SI. Critical analysis of the use of computer-assisted transverse axial tomography to study human brain in aging and dementia of the Alzheimer type. Neurol 1990; 40: 872-83.

17. Odebode TO, Shokunbi MT, Malomo AO, Familusi JB, Agbeja-Baiyeroju AM, Ogunseyinde AO. The relationship between ventricular size and visual function in children with hydrocephalus. Afr $J$ Med Med Sci 1998; 27: 213-8.

18. Ebruke B, Tongo O, Sofoluwe A, Orimadegun B, Obajimi M. Intracranial ventricular sizes and correlates in term Nigerian infantsat birth and six weeks. Afr J Med Sci 1988; 27: 213-8.

19. Gyldensted C, Kosteljanetz M. Measurements of the normal ventricular system with computer tomography of the brain. A preliminary study on 44adults. Neuroradiol 1976; 10: 205-13.

20. Skullerud K. Variations in the size of the human brain. Influence of age, sex, body length, body mass index, alcoholism, Alzheimer changes, and cerebral atherosclerosis. Acta Neurol Scand Suppl 1985; 102: 1-94.

21. Haug G. Age and sex dependence of the size of normal ventricles on computed tomography. Neuroradiol 1977; 14: 201-4.

22. Evans Jr WA. An encephalographic ratio for estimating the size of the cerebral ventricles: further experience with serial observations. Am J Dis Child 1942; 64: 820-30.

23. Khan G, Khan N, Aziz A. Detection of cerebral atrophy in type-II diabetes mellitus by magnetic resonance imaging of brain. J Ayub Med Coll Abbottabad 2010; 22: 67-70.

24. Hiraoka K, Meguro K, Mori E. Prevalence of idiopathic normal-pressure hydrocephalus in the elderly population of a Japanese rural community. Neurol Med Chir 2008; 48: 19799. discussion 9-200. PMID: 18497491 [Epub 2008/05/24.eng].

25. Kosourov AK, Ga ^uvoronski`1 IV, Rokhlin GD, Blagova IA, Panfilenko AF. [In vivo assessment of various parameters of the brain ventricles with magnetic resonance tomography]. Morfologiia (Saint Petersburg Russia) 2002; 122: 71-73.

26. Patnaik P, Singh V, Singh D, Singh S. Age and gender related variations in lateral ventricle brain ratios. Int'l J Health Sci Res 2016; 6: 78-84.

27. Skullerud K. Variations in the size of the human brain. Influence of age, sex, body length, body mass index, alcoholism, Alzheimer changes, and cerebral atherosclerosis. Acta Neurol Scand Suppl 1985; 102: 1-94.

28. Kumar SA, Kumari SM, Anand VM, Sarawathy R, Rajeshwari M. Evaluation of Evan's Index 
in South Indian Population using Computed Tomography. Int'l J Ant Radio Surg 2017; 6: 28-31.

29. Patnaik P, Singh V, Singh S, Singh D. Lateral ventricle ratios correlated to diameters of cerebrum-A study on ct scans of head. J Anat Sci 2014; 22: 5-11.

30. Tullberg M, Jensen C, Ekholm S, Wikkelsø C. Normal pressure hydrocephalus: vascular white matter changes on MR images must not exclude patients from shunt surgery. Am J Neuroradiol 2001; 22: 1665-673.

31. Synek V, Tuben JR, DuBoulay GH. Comparing Evans' Index and computerized axial tomography in assessing relationship of ventricular size to brain size. Neurol (NY) 1976; 26: 231-3 .
32. Meese W, Kluge W, Grumme T, Hopfenmuller W. CT evaluation of the CSF spaces of healthy persons. Neuroradiol 1980; 19: 131-6. PMID: 6966769 [Epub 1980/04/01.eng].

33. Coffey CE, Figiel GS, Djang WT, Weiner RD. Sub cortical hyper intensity on magnetic resonance imaging: a comparison of normal and diepressed elderly subjects. Am J Psychiatr 1990; 147: 187-9.

34. Wilk R, Kluczewska E, Syc B, Bajor G. Normative values for selected linear indices of the intracranial fluid spaces based on CT images of the head in children. Polish J Radiol/ Polish Med Soc Radiol 2011; 76: 16-25. PMID: 22802837 